\title{
Evaluation of Genetic Diversity in Wild Celtis australis L. Genotypes using Multivariate Analysis
}

\author{
Arshad Khan ${ }^{1}$, Mohammad Ihsan ${ }^{1}$, Ali Hazrat ${ }^{1 *}$, Mohammad Nisar ${ }^{1}$, Muhammad Laiq ${ }^{1}$, Maryam Bibi ${ }^{1}$, \\ Nasir Ali ${ }^{2}$, Ulfat $\mathrm{Naz}^{1}$, Muhammad Zakria ${ }^{1}$, Nausheen Nazir ${ }^{3}$, Adam Khan ${ }^{4}$ and Muhammad Asif Nawaz
}

${ }^{1}$ Department of Botany, University of Malakand Chakdara, Dir Lower, Khyber Pakbtunkhwa, Pakistan; ${ }^{2}$ Department of Botany, Hazara University Mansehra, Khyber Pakbtunkhwa, Pakistan; ${ }^{3}$ Department of Biochemistry, University of Malakand Chakdara, Dir Lower, Khyber Pakbtunkbwa, Pakistan; ${ }^{4}$ Department of Biological Sciences, University of Lakki Marwat, Khyber Pakbtunkhwa, Pakistan; ${ }^{5}$ Department of Biotechnology, Shaheed Benazir Bhutto University Sheringal, Dir Upper Khyber Pakhtunkhwa, Pakistan.

\begin{abstract}
Celtis australis L. is one of the most important annual plants globally. The current study was conducted to evaluate Celtis australis genotypes through morphological and biochemical characterizations. A total of 80 genotypes were collected from different regions of district Dir and Swat, Khyber Pakhtunkhwa Pakistan, and were characterized for 11 phenotypic traits (4 qualitative and 7 quantitative). A significant diversity was found for leaf length with the range of 4 to $15 \mathrm{~cm}$, leaf width 1 to $7.0 \mathrm{~cm}$, petiole length range from 0.5 to $4.5 \mathrm{~cm}$. The internodes length ranged from $0.5 \mathrm{~cm}$ to 6 . The seed length ranged from 4 to $11 \mathrm{~mm}$. The 100 seed weight ranged from 7.7 to $48 \mathrm{~g}$. Correlation analysis revealed that leaf width was strongly significant with leaf length $\left(0.454^{* *}\right), 100$ seed weight with leaf length $\left(0.289^{* *}\right)$, seed width was also found strongly significant with seed length $\left(0.246^{*}\right)$, and 100 seed weight was found significant with seed length $\left(0.236^{*}\right)$. On the basis of Cluster analysis, all the genotypes were divided into two linkages and further divided into 7 sub clusters. Every group showed less difference to one another but high variation to other groups. Similarly, in total seed storage proteins, a total of 13 polypeptides bond were found with the total genetic diversity of $(0.68 \%)$ found in band 1 , while in band 2 , the variation was $0.63 \%$. A cluster dendogram was constructed for total seed storage proteins and divided 7 sub clusters, where CA1 and CA69 were found the most diverse genotypes. The main aim of this study was to explore morphological variation in order to generate data that could assist in determining the most appropriate tools that are adaptable to various environments.

Received | March 18, 2021; Accepted | June 18, 2021; Published | October 05, 2021

*Correspondence | Ali Hazrat, Department of Botany, University of Malakand Chakdara, Dir Lower, Khyber Pakhtunkhwa, Pakistan; Email: aliuom@gmail.com

Citation | Khan, A., M. Ihsan, A. Hazrat, M. Nisar, M. Laiq, M. Bibi, N. Ali, U. Naz, M. Zakria, N. Nazir, A. Khan and M.A. Nawaz. 2021. Evaluation of genetic diversity in wild Celtis australis L. genotypes using multivariate analysis. Sarhad Journal of Agriculture, 37(4): 1418-1425. DOI | https://dx.doi.org/10.17582/journal.sja/2021/37.4.1418.1425

Keywords | Celtis australis L., Cluster analysis, Correlation analysis, Genetic heritability, Principle component analysis
\end{abstract}

\section{Introduction}

C eltis australis L. is one of the important plant belong to the family Ulmaceae which is one of the largest family of about 15 genera and 200 species. Celtis occidentalis L. are commonly cultivated for shade purposes in Egyptian gardens (Singh et al., 2006). Celtis australis is a deciduous tree commonly known as the European nettle tree or Mediterranean hackberry. Hackberry fruits are seldom used for nutritional purposes. The nutritional and physicochemical properties, including water, total fiber, protein, 
vitamins, minerals and phenolic material of ripe hackberry fruit from Istria have been determined (Ota et al., 2017). This is attributed to many benefits, including the elevated stability of seed proteins that are not influenced by environmental conditions (Fischer et al., 2012). The leaf and fruit of this herbal specie are used for the treatment of amenorrhea, extreme menstruation and intermenstrualization of blood and colon (Mazzocchi, 1999). In medicine, immature fruit is often considered very effective.

Celtis is grown in rain fed agriculture for fodder, fuel, timber and various other uses in or around agricultural fields and plays a vital role in the socioeconomic structure of hilly people by supplying livestock with highly palatable, nutritious and tannin-free green fodder, particularly during the time of scarcity of green fodder (Yadav and Bisht, 2015). The geographic regions and climate in which parent trees have evolved and within which their genetic structure has been produced through natural and artificial selection result in differences between the species' natural populations (Morgenstern, 2011).

In order to effectively conserve, evaluation and use of germplasm, it is important to investigate the degree of available genetic diversity. Genetic diversity is an integral component of any agricultural production system. Since a breeding program, it is based on the magnitude of genetic variability; morphological characterization is considered to be one of the significant steps in classification of crop improvement in a germplasm (Wisal et al., 2019; Arshad et al., 2019). Total Seed protein profiling, obtained by electrophoresis of polyacrylamide gel (PAGE), is also one of the commonly used in taxonomy to provide reliable evidence to answer different taxonomic problems and has been widely used to resolve systematic relationships (Karihaloo et al., 2002). Analysis of their morphological heterogeneity, genetic and chemical and agronomic characterization. Moreover, it should be noted that in their natural habitat, this species is undergoing loss. The value of variability occurs for this reason. Celtis australis is threatened by ecological upheavals caused by deforestation, overgrazing, agricultural mechanization and urbanization, like all forest species (Ammari et al., 2016). SDS-PAGE is considered a practically reliable method because seed storage proteins are largely independent of fluctuations in the environment. Our knowledge of the potential and objective diversity of wild plant species is still limited and needs to be improved (Bozchaloyi et al., 2017).

The current, slight consideration has been paid to wild plants, so the main objective of the current study was to assess intra-specific genetic variation within the naturalized population of Celtis australis in different geographical regions. The present research was planned to study genetic relationships between natural Celtis australis populations collected for morphological and seed storage protein evaluation collected from two districts.

\section{Materials and Methods}

\section{Morphological traits}

The present study was carried out in October 2020 at Department of Botany University of Malakand, Pakistan. A total of 11 morphological characters were investigated (four qualitative and seven quantitative). Kernel color, seed shape, shell texture, seed color, leaf length, leaf width, petiole length, internodes length, seed length, seed width, and 10 seed weight are among the agro morphological traits with the highest frequency.

\section{Biochemical characterization}

All the collected genotypes used in agro morphological characterizations, were subjected to total seed storage proteins based on SDS-PAGE analyses. 3 healthy and mature seed were manually grinded with mortar and pestle. Of the grinded sample, $0.02 \mathrm{~g}$ was weighed and transferred to $1.5 \mathrm{ml}$ centrifuge tubes, where $400 \mu \mathrm{l}$ protein extraction buffer was added to the tube. The powder was homogenized through vortex for 1 minute before centrifugation at $12,000 \mathrm{rpm}$ for 10 minutes at room temperature (RT). For total seed protein $12.25 \%$ polyacrylamide gels were used, follow the protocol of Nisar et al. (2016).

\section{Data analysis}

To estimate the genetic diversity 5 plants were randomly selected and then the mean values of each genotype were used for data analysis. Basic statistics (Mean, Maximum, Minimum, and Coefficient of variance) was calculated using Microsoft Excel 2010. A total of 11 morphological traits were recorded and examined by using cluster as well as principal component analysis. Correlation analysis was computed using Statistical 7 (Applied Biostatistics Inc, USA). 
For total seed storage proteins binary matrix data was calculated as presence and absence of bands. For cluster analysis, dendogram was computed using unweighted pair group method with arithmetic average (UPGMA) algorithm. The electrophoresis band spectra and similarity index was calculated for possible pairs of electrophograms following Nisar et al. (2016).

\section{Results and Discussion}

\section{Agro-morphological evaluation}

A total of 80 landraces of Celtis australis were evaluated for agro morphological and biochemical characterizations. 11 morphological characters were investigated (four qualitative and seven quantitative). Kernel color, seed shape, shell texture, seed color, leaf length, leaf width, petiole length, internodes length, seed length, seed width and 100 seed weight are among the agro morphological traits with the highest frequency. High variability in grain yield and biomass indicated that simple selection could be used to increase grain yield and biomass in different crops (Coulibaly et al., 2002). The detection and estimation of genetic diversity is a crucial step in the competent and efficient conservation and use of various crop germplasm (Ghafoor, 2005). All plant breeders must therefore evaluate and classify their plants using agro morphological traits (Martins et al., 2006). Morphological features serve as a basis for germplasm evolution. However, genetic markers can have a range of disadvantages when it comes to morphological characteristics.

\section{Qualitative characters}

During the present study two type of kernel cover were observed (12.5\%) genotypes shows green and $(87.5 \%)$ have yellow kernel cover. Diversity was also found in seed shape such as round (90\%) and oval (10\%), while the shell texture was found hard (2.5\%), semi hard (92.5\%), soft (5\%). Three type of seed color was found, $57.5 \%$ white, black $37.5 \%$, while $5 \%$ was yellow. Despite the fact that quantitative characters are affected by environmental factors, conservationists should not overlook or dismiss them in crop diversity research (Ebrahim et al., 2015).

\section{Quantitative characters}

During the present work 7 quantitative traits were studied. A significant diversity was found for most of the traits. During the current work the leaf length was found with the range of 4 to $15 \mathrm{~cm}$ with the mean value of 8.46, standard deviation of 2.24 sample variance of 5.05 . The range of leaf width was $1 \mathrm{~cm}$ to $7.0 \mathrm{~cm}$, with the mean value of $3.6 \mathrm{~cm}$ standard deviation of 1.18 and sample variance of 1.39 . The petiole length divided into three groups, range from $0.5 \mathrm{~cm}$ to $4.5 \mathrm{~cm}$, with the mean value 1.36 standard deviation of 0.53 , sample variance 0.28 . The internodes length was studied in the population. The internodes length ranges from $0.5 \mathrm{~cm}$ to 6 with a mean value 2.21 standard deviation of 0.88 , sample variance 0.78 . The seed length was studied in the population showing the range from 4 to $11 \mathrm{~cm}$ with the mean value of the fruit length ranges from 4 to $11 \mathrm{~mm}$ with a mean value 7.49 , standard deviation of 1.74 , sample variance 3.01. Leaf width range from 4 to 11 with the mean value of 7.48 sample variance 2.91 . The 100 seed weight was studied in the population. The 100 seed weight range from 7.7 to $48 \mathrm{~g}$ with a mean 24.7 value sample variance 0.73 (Table 1). According to ElAlfy et al. (2011) same result for australis. The finding was intimately associated with that of Ghafoor et al. (2005) which reported in different crops species.

\section{Correlations}

The correlation, mean and standard variation was estimated. The result showed strong correlation between morphological variables of Celtis australis L. The correlation matrix of Pearson (n) indicates that there are negative correlations and other positive between variables taken two by two.MS Excel was used to perform correlation analysis for seven agro morphological characters of 80 Celtis australis landraces. There were a total of 21 Correlation coefficient values found, 17 of which were positive and 4 of which were negative (Table 2). Correlation of plant leaf length $\left(0.454^{* *}\right)$, leaf width, petiole length also positive correlated with leaf length $(.282 *)$, leaf length were positive correlated with 100 seed weigh $\left(.289^{* *}\right)$, seed width was strong positive correlated with seed length $\left(.677^{* *}\right)$, and also positive correlate with 100 seed weight .246*, and seed width also positive correlate with 100 seed width $\left(.236^{*}\right)$, petiole length negative correlate with leaf length -0.015 , inter node length were negative correlate with seed width -0.135 . Our results are in close agreement with that of (Ammari et al., 2016) where the contributors found significant correlation in plant height and crown height $(-0.747)$ and with the diameter of the crown (-0.508) in Celtis specie. 
Table 1: Descriptive static of seven quantitative traits.

Traits Mean Std. Std. Sample Mini- Maxi- CV\% Er- devia- vari- mum mum ror tion ance

$\begin{array}{llllllll}\text { LL } & 8.46 & 0.25 & 2.24 & 5.04 & 4 & 15 & 178.24 \\ \text { LW } & 3.51 & 0.13 & 1.18 & 1.39 & 1 & 7 & 84.75 \\ \text { PL } & 1.36 & 0.06 & 0.53 & 0.28 & 1 & 3 & 187.43 \\ \text { IL } & 2.21 & 0.10 & 0.88 & 0.78 & 1 & 5 & 113.44 \\ \text { SL } & 7.49 & 0.19 & 1.74 & 3.01 & 4 & 11 & 230.46 \\ \text { SW } & 7.48 & 0.19 & 1.71 & 2.91 & 4 & 11 & 234.45 \\ \text { 100S/w } & 24.7 & 0.10 & 0.86 & 0.73 & 7.7 & 48 & 89.85\end{array}$

Table 2: Correlation of 7 quantitative traits among 80 Celtis australus $L$.

$\begin{array}{llllllll}\text { Traits } & \text { LL } & \text { LW } & \text { PL } & \text { IL } & \text { SL } & \text { SW } & \text { 100S/W } \\ \text { LL } & 1 & & & & & & \\ \text { LW } & .454^{* *} & 1 & & & & & \\ \text { PL } & -0.015 & 0.144 & 1 & & & & \\ \text { IL } & .282^{*} & 0.077 & 0.103 & 1 & & & \\ \text { SL } & 0.097 & -0.08 & 0.025 & 0.039 & 1 & & \\ \text { SW } & 0.157 & -0.009 & 0.017 & -0.135 & .677^{* *} & 1 \\ \text { 100S/w } & .289^{* *} & 0.095 & -0.004 & 0.083 & .246^{*} & .236^{*} 1\end{array}$

Cluster analysis for quantitative traits

Cluster dendogram was constructed for agromorphological characters using Ward's Method all the genotypes were split into two linkages, and further divided into 7 sub cluster (Figure 1). Each group members shows less variation to one another but shows large number of diversity with the other groups. Cluster 1 consist of CA01, CA11, CA49, CA20, CA21, CA33, CA30, CA12,CA54, CA26, CA27, CA29, CA65, CA25, CA74, CA76, CA79, cluster 2 consist of CA10, CA60, CA15, CA46, CA64, CA75, CA72, CA34, CA69, CA29, CA62, CA63, CA80, CA35, CA38, CA41, cluster 3 consist of CA42, CA53, CA52, CA45, CA44, CA55, CA47, cluster 4 have CA02, CA66, CA78, CA07, CA73 while cluster 5 have CA04, CA24, CA14, CA19, CA66, CA16, CA77, CA17, CA32, CA28, cluster 6 have CA03, CA22, CA13, CA68, CA05,CA57,CA58, CA61, CA59, CA08, CA09, CA70, CA31, CA18, cluster 7 have CA37, , CA71, CA56, CA67, CA40, CA43, CA39, CA48, CA56, CA51 genotypes. Who divided agro morphological traits into four clusters and reported the same result. According to (Iqbal et al., 2005), the variation within and between regions

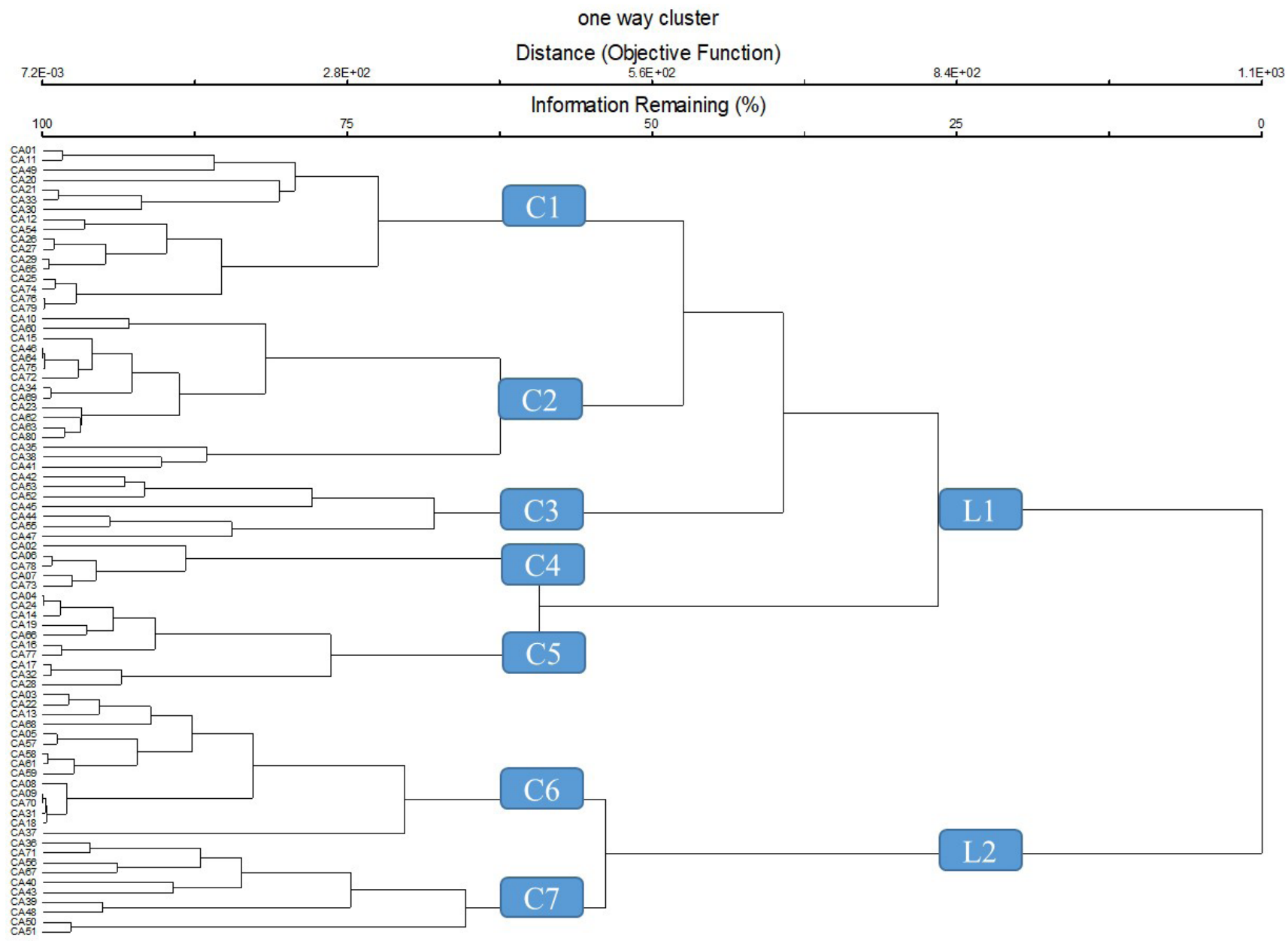

Figure 1: Cluster dendogram for 7 quantitative traits of 80 Celtis ausrtilus.

December 2021 | Volume 37 | Issue 4 | Page 1421 


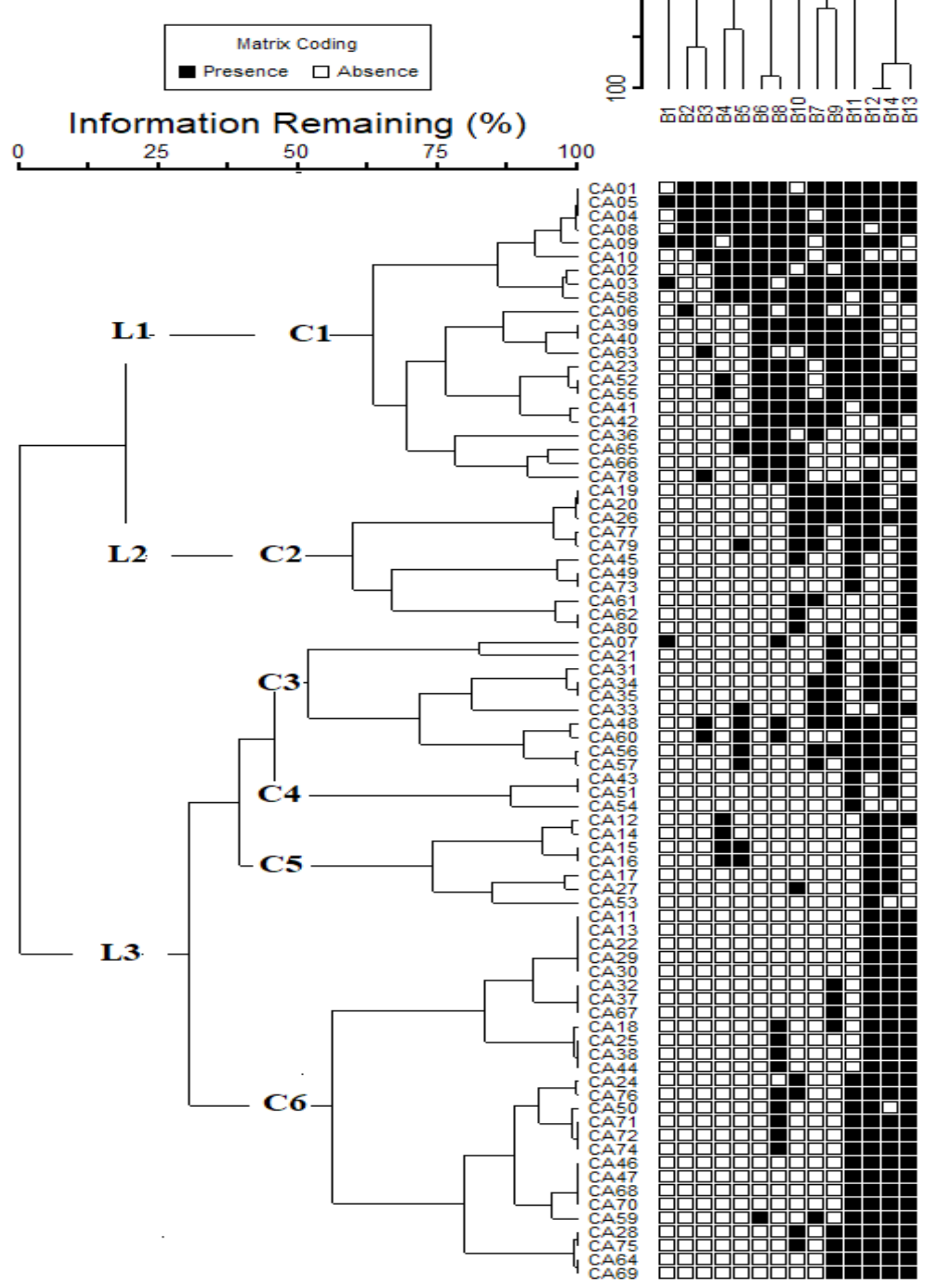

Figure 2: Two way Cluster dendogram of protein profiling of 80 genotypes of Celtis australus $L$. 
Total seed protein

represents variations in quantitative traits, and the geographic source of genetic variability is known also Wisal et al. (2019) reported the same result in different species of acacia.

The biochemical analysis using SDS-PAGE has great contribution for the estimation of genetic diversity (Zahoor et al., 2015). Since form a few years it was estimated that in different crop species has dependent on morphological character (Khan et al., 2016), However, biochemical approaches are now commonly used to investigate genetic variation, which has more benefits than conventional morphology (Ndiaye et al., 2011). For the protein profiling SDSPAGE is a biochemical technique which is widely used for identification genetic structure of different crops because it is simple, reliable and free from fluctuation (Ghafoor et al., 2005). The researchers approved that biochemical analysis of protein by SDS PAGE provided valid evidence for detecting intra specific variation and assessing inter specific relationships (Hameed et al., 2009; Irfan et al., 2010). SDS-PAGE study of the protein profile of 80 genotypes of Celtis australis showed fourteen reproducible bands (Figure 2). During the present, there has been a large amount of diversity discovered. B1 has the highest overall genetic diversity $(0.68 \%)$, followed by B2 (0.63\%) and B3 (0.49\%) polymorphism, and B5 (0.48\%), B9 (0.43\%), B6 and B8 (0.42\%) polymorphism, respectively. Similarly, B12 (0.39 percent) showed low levels of B4, B7 (0.38 percent), B13 (0.35 percent), $\mathrm{B} 11$ (0.28 percent), B10 (0.27 percent), and B14 (0.27 percent) (0.20 percent). On the basis of difference in their protein profiles, a genetic tree based on protein binary data matrix divides 80 genotypes of Celtis australis into several clusters. The dendogram was found to divide landraces into three linkages: L-1, L-2, and L-3 and further divided into 6 clusters in these two linkages. The sub cluster 1 consist of CA01, CA05, CA04, CA08, CA09, CA10, CA02, CA03, and CA58, CA06, CA39, CA40, CA63, CA23, CA52, CA55, CA41, CA42, CA36, CA65, CA66, CA78 genotypes and cluster 2 have CA19, CA20, CA26, CA77, CA79, CA45, CA49, CA73, CA61, CA62, CA80 genotypes while cluster 3 have CA07, CA21, CA31, CA34, CA35, CA33, CA48, CA60, CA56, CA57, genotypes. Cluster 4 comprises CA43, CA51, and CA54. Cluster 5 comprises CA12, CA14, CA15, CA16, CA17, CA27, CA53 genotypes while cluster 6 have CA11, CA13, CA13, CA22, CA29, CA30, CA32, CA37, CA67, CA18, CA25,

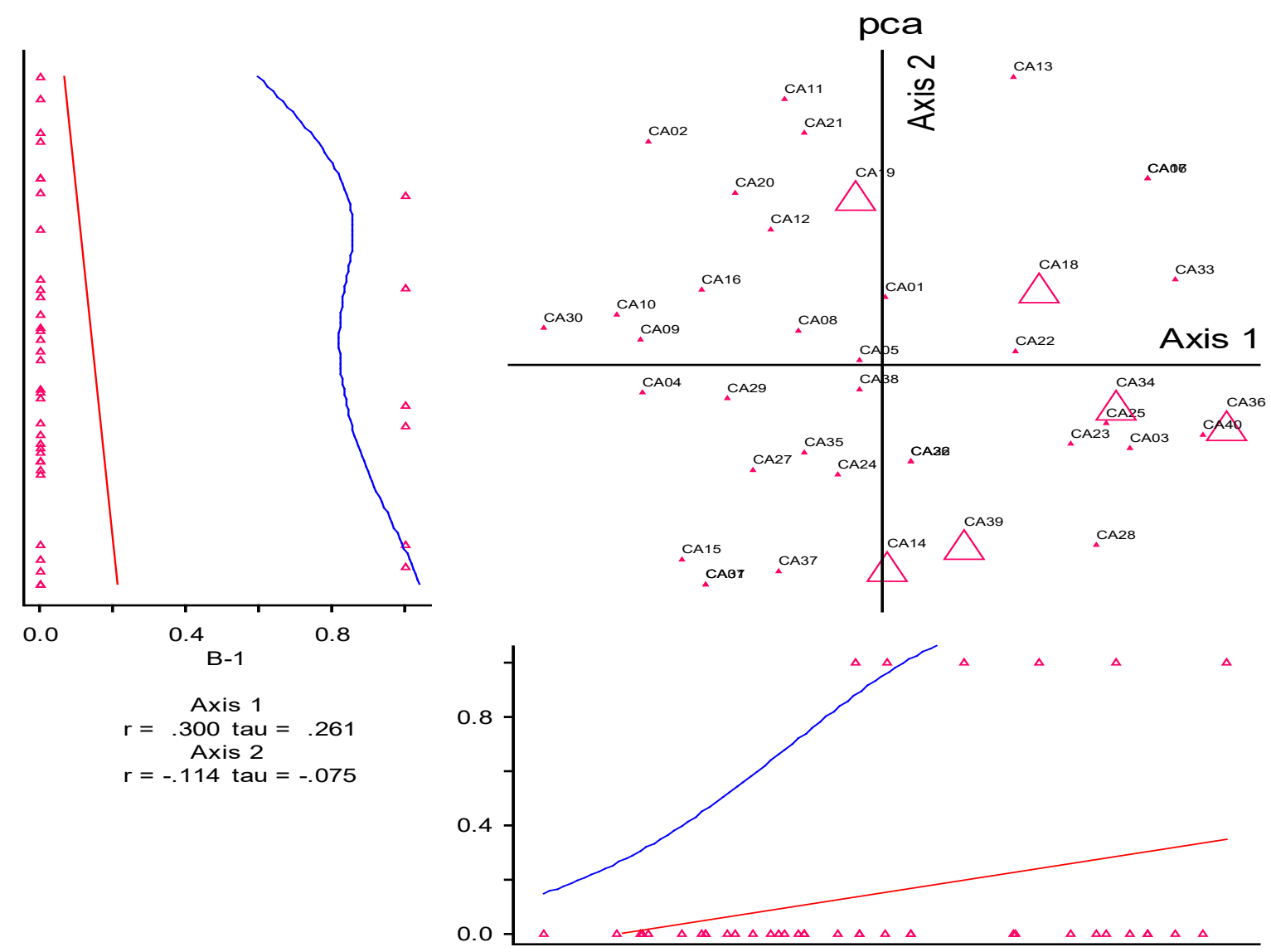

Figure 3: Scatter plot for protein data of 80 genotype of Celtis. 
CA38, CA44, CA24, CA76, CA50, CA71, CA72, CA74, CA46, CA47, CA68, CA70, CA59, CA28, CA75, CA64, CA69 genotypes respectively. For the further confirmation of genetic divergence among the genotype of Celtis scatter plot were used (Figure 3) Plant breeders will benefit from the substantial amount of genetic diversity found within the banding pattern in potential breeding efforts. Similarly, in other plants for genetic diversity (Nisar et al., 2016), the same finding was published.

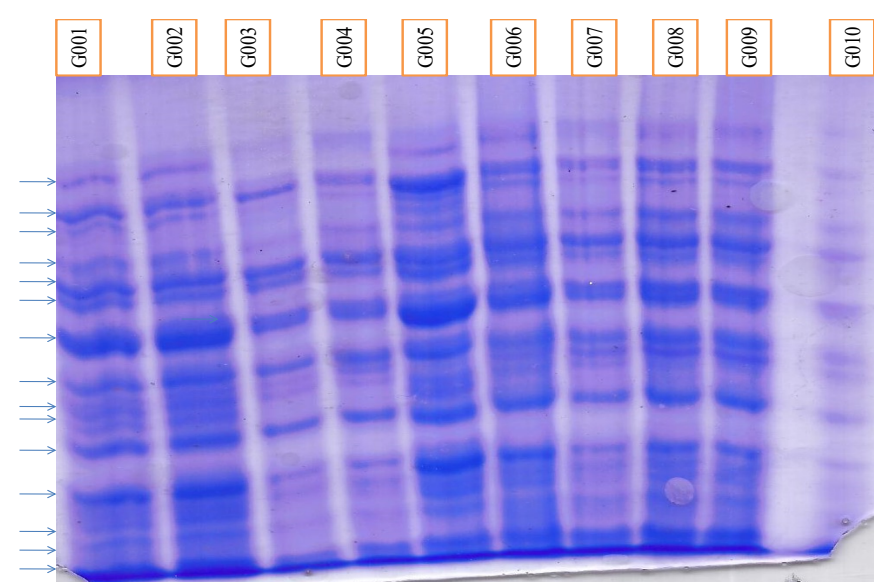

Figure 4: Gel electrophoreses protein bands pattern of Celtis australus $L$.

\section{Conclusions and Recommendations}

Maximum variation was observed in seed length, seed width, and 100 seeds weight and these characters were found useful for selection of candidate's lines. On the basis of cluster analysis genotypes CA01 and CA51 were found the most diverse while on the basis of total seed storage protein genotype CA01 and CA69 were found the most diverse and can be used for future breeding programs. A considerable variation was observed in SDS-PAGE analyses of seed storage protein were also done which give significant result, in total of 14 bands were observed found variation among the cluster. It was suggested that representative genotype from different clusters could be chosen for the future hybridization program.

\section{Novelty Statement}

This study aimed to identify diversity in wild Celtis australis in the hilly areas. This activity was novel and was not carried out in this area.

\section{Author's Contribution}

Arshad Khan: Conducted research and data collection.

Mohammad Ihsan and Ali Hazrat: Results calibration.

Mohammad Nisar and Muhammad Zakria:

Discussion calibration.

Muhammad Laiq: Helped in data collection.

Maryam Bibi and Nasir Ali: References setting.

Ulfat Naz and Nausheen Nazir: Review of the literature.

Adam Khan and Muhammad Asif Nawaz: Helped in proofreading.

\section{Conflict of interest}

The authors have declared no conflict of interest.

\section{References}

Ammari, Y., R. Zouaoui, M. Abbasi, S. Jebali and S. Hamdi. 2016. Study of dendrometric and morphological variability of Celtis australis located in Northern Tunisia. Int. J. Agric Inno. Res., 5(3).

Arshad, K., M.A. Ul-Haq, R. Khan, K. Gul, K. Khan, A. Khan and I. Iqbal. 2019. Evaluation of wild Rhynchosia minima (L.) DC. Through morphometric and biochemical markers. Int. J. Biosci.,14(2): 7-15. https://doi.org/10.12692/ ijb/14.3.7-15

Bozchaloyi, S.E., M. Sheidai, M. Keshavarzi and Z. Noormohammadi. 2017. Genetic and morphological diversity in Geranium dissectum (Sec. Dissecta,Geraniaceae) populations. Biologia, 72(10): 1121-1130. https://doi. org/10.1515/biolog-2017-0124

Coulibaly, S., R.S. Pasquet, R. Papa and P. Gepts. 2002. AFLP analysis of the phonetic organization and genetic diversity of Vigna unguiculata $\mathrm{L}$. Walp. Reveals extensive gene flow between wild and domesticated types. Theor. Appl. Genet., 104(2-3): 358-366. https://doi. org/10.1007/s001220100740

Ebrahim, S., E. Shiferaw and F. Hailu. 2015. Evaluation of genetic diversity in barley (Hordeum vulgare L.) from Wollo high land areas using agro-morphological traits and hordein. Afr. J. Biotechnol., 14(22): 217-225.

El-Alfy, T.S.M., H.M.A. El-Gohary, N.M. Sokkar, S.A. El-Tawab and D.A.M. Al-Mahdy. 2011. Botanical and genetic characteristics of Celtis australis L. and Celtis occidentalis L. grown in Egypt. Bull. Fac. Pharm. Cairo 
Univ., 49(1): 37-57. https://doi.org/10.1016/j. bfopcu.2011.07.007

Fischer, R., S. Schillberg, S. Hellwig, R.M. Twyman and J. Drossard. 2012. GMP issues for recombinant plant-derived pharmaceutical proteins. Biotechnol. Adv., 30(2): 434-439. https:// doi.org/10.1016/j.biotechadv.2011.08.007

Ghafoor, A., Z. Ahmad and M. Afzal. 2005. Use of SDS-PAGE markers for determining quantitative traits loci in black gram [Vigna mungo (L.) Hepper] germplasm. Pak. J. Bot., 37(2): 263.

Hameed, A., T.M. Shah, B.M. Atta, N. Iqbal, M.A. Haq and H. Ali. 2009. Comparative seed storage protein profiling of Kabuli chickpea genotypes. Pak. J. Bot., 41(2): 703-710.

Iqbal, S.H., A. Ghafoor and N. Ayub. 2005. Relationship between SDS-PAGE markers and Ascochyta blight in chickpea. Pak. J. Bot., 37(1): 87-96.

Irfan, M., and S. Matthias. 2010. Encapsulation using hyper branched polymers from research and technologies to emerging applications. Ind. Eng. Chem. Res., 49: 1169-1196. https://doi. org/10.1021/ie900216r

Karihaloo, J.L., M. Kaur and S. Singh. 2002. Seed protein diversity in Solanum melongena L. and its wild and weedy relatives. Genet. Resor. Crop Eval., 49(6): 533-539. https://doi. org/10.1023/A:1021288108928

Khan, A., Z.K. Shinwari and A. Iqbal. 2016. Conventional breeding enhances genetic diversity in Pisum sativum (L.) detected through SDS-page. Pak. J. Bot., 48(6): 2433-2438.

Khan, J., A.H. Shah, M. Nisar, N. Ali, U. Khan, W. Khan and H. Ahmad. 2016. Evaluation of genetic diversity in Black gram through SDS-PAGE. Plant Cell Biotechnol. Mol. Biol., 17(3): 4.

Martins, L.L. and M.P. Mourato. 2006. Effect of excess copper on tomato plants: growth parameters, enzyme activities, chlorophyll, and min- eral content. J. Plant Nutr., 29(12): 2179-2198. https://doi.org/10.1080/01904160600972845

Mazzocchi, M., 1999. Implementation of the event study methodology to agricultural markets: An evaluation of the BSE impact on cattle prices in Italy. Cahiers Econ. Sociol. Rurales, 50: 36-53.

Morgenstern, M., 2011. Geographic variation in forest trees: Genetic basis and application of knowledge in silviculture. UBC press.

Ndiaye, M., C. Philippe, H. Mukhtar and N. Ahmad. 2011. The grape antioxidant resveratrol for skin disorders: Promise, prospects, and challenges. Arch. Bioch. Biophy., 508(2): 164170.https://doi.org/10.1016/j.abb.2010.12.030

Nisar, M., A. Ghafoor, S.F. Wadood, A. Iqbal and Nausheen. 2016. Intra and inter specific profiling of Pakistani Quercus species growing in the hilly areas of district Dir Khyber. Pak. J. Bot., 48(1): 263-270.

Ota, A., A.M. Visnjevec, R. Vidrih, Z. Prgomet, M. Necemer, J. Hribar and N.P. Ulrih. 2017. Nutritional, antioxidative, and antimicrobial analysis of the Mediterranean hackberry (Celtis australis L.). Food Sci. Nutr., 5(1): 160-170. https://doi.org/10.1002/fsn3.375

Singh, B., B.P. Bhatt and P. Prasad. 2006. Variation in seed and seedling traits of Celtis australis, a multipurpose tree, in Central Himalaya, India. Agrofor. Syst., 67(2): 115-122. https:// doi.org/10.1007/s10457-004-2948-x

Wisal, S., A. Khan, K. Gul, W. Khan, G. Nigar and M. Ali. 2019. Assessing genetic variability index among species of ACACIA through morphological and biochemical markers. Int. J. Biosci., 14: 388-401. https://doi.org/10.12692/ ijb/14.1.388-401

Yadav, R.P. and J.K. Bisht. 2015. Celtis australis Linn: A multipurpose tree species in north west Himalaya. Int. J. Life-Sci. Sci. Res., 1: 66-70.

Zahoor, M., M. Nisar and N. Islam. 2015. Genetic variations of Robinia pseudoacacia plantusing SDS-PAGE. Pak. J. Bot., 46(6): 2335-2338. 